\title{
Bringing home unwelcome souvenirs: Travel and drug-resistant bacteria
}

\author{
BJ Langford ${ }^{1,2}, \mathrm{KL} \mathrm{Schwartz}^{1,2,3 *}$
}

\begin{abstract}
Antimicrobial resistance poses a significant threat to public health globally and in Canada. Wide regional variability in antimicrobial resistance and ongoing increases in global travel present an important risk for the acquisition and transmission of drug-resistant organisms. Travel from high-income to low- and middle-income countries, particularly the Indian subcontinent, present the greatest risks for acquiring a drug-resistant Enterobacteriaceae. Risk factors for returning from travel with drug-resistant organisms include seeking medical care while abroad, travellers' diarrhea and antibiotic use. Health care professionals can play an important role in preventing harm for travellers by counselling patients on the risks of acquiring drug-resistant organisms, appropriate antibiotic prescribing for travellers' diarrhea and tailored empiric therapy for patients presenting with infection after travel.
\end{abstract}

\author{
Affiliations \\ ${ }^{1}$ Public Health Ontario, Toronto, \\ ON \\ 2 St. Joseph's Health Centre, \\ Toronto, ON \\ ${ }^{3}$ Dalla Lana School of Public \\ Health, Toronto, ON \\ ${ }^{\star}$ Correspondence: \\ kevin.schwartz@oahpp.ca
}

Suggested citation: Langford BJ, Schwartz KL. Bringing home unwelcome souvenirs: Travel and drug-resistant bacteria. Can Commun Dis Rep 2018;44(11):277-82. https://doi.org/10.14745/ccdr.v44i11a02

Keywords: antimicrobial resistance, travel, antimicrobial stewardship, infection prevention and control, medical tourism

\section{Introduction}

Antimicrobial resistance (AMR) is a growing problem globally. It is identified as one of the most significant public health threats of our time. In the absence of meaningful intervention, it is estimated that deaths from drug-resistant infections will increase from 700,000 to 10 million annually by 2050, surpassing current cancer rates as the number one cause of death (1). Moreover, the prevalence of drug-resistant organisms across the globe varies widely. For example, resistance of Escherichia coli to third-generation cephalosporins is much more common in India, at $78 \%$, than in Canada, at $9 \%(2)$.

In this global society, AMR knows no borders. In 2017, the number of passengers using air travel exceeded four billion for the first time; this number is forecast to double by 2036 (3).

One of the big challenges of AMR with respect to travel is infections from drug-resistant Enterobacteriaceae.

Enterobacteriaceae are a large family of gram-negative bacilli that can cause a wide range of infections including those affecting the urinary, respiratory and gastrointestinal tracts. Organisms in this family include E. coli, Klebsiella species, Enterobacter species and Salmonella species. A key mechanism of Enterobacteriaceae antibiotic resistance is the development of beta-lactamase and carbapenemase enzymes, which hydrolyze beta-lactam antibiotics, rendering them ineffective. Genes for these enzymes are commonly encoded by plasmids, which can transfer between bacterial organisms. Key groups of Enterobacteriaceae resistance are extended-spectrum beta-lactamase-producing Enterobacteriaceae (ESBL-PE), and carbapenem-resistant Enterobacteriaceae (CRE). Of growing importance is the plasmid-mediated colistin-resistance gene mcr-1. The ability of bacteria to transfer antimicrobial resistant genes to one another via plasmids poses significant infection control challenges. A rise in Enterobacteriaceae resistance translates to more infection-related mortalities, longer hospital stays and increased costs to the health care system $(4,5)$.

The objective of this article is to describe the clinically relevant risk of drug-resistant organisms associated with travel, with a focus on Enterobacteriaceae. For the purposes of this review, travel is defined as movement of people travelling to low- and middle-income countries in Asia, Africa and the Americas, and returning to high-income countries such as Australia, Canada, New Zealand, United States (US) and those in Europe. 


\section{What is the risk of bringing home drug-resistant bacteria after travel?}

The studies on the risk of travellers acquiring either ESBL-PE or CRE are sobering and have important considerations to the management of patients in Canada.

\section{Extended-spectrum beta-lactamase-producing Enterobacteriaceae (ESBL-PE)}

One of the largest studies to evaluate the risk of acquiring a drug-resistant organism during travel focused on the importation of ESBL-PE to the Netherlands. Through a longitudinal cohort study of 2001 travellers, the authors determined the likelihood of ESBL-PE colonization before and after the travel period. Of those individuals who did not have an ESBL-PE prior to travel, $34 \%$ acquired an ESBL-PE while abroad (6). There was marked variability in the risk of ESBL-PE colonization associated with the region visited. Travel to southern Asia presented the highest risk, at $75 \%$ incidence of colonization, followed by central and eastern Asia (49\%), western Asia (43\%), southeastern Asia (37\%), the Caribbean and Central America (28\%), middle and eastern Africa $(28 \%)$, western Africa (19\%), South America (18\%) and southern Africa (6\%). The median duration of colonization after travel was 30 days (95\% confidence interval [CI]: 29-33 days). However, $11.3 \%$ remained colonized after 12 months, highlighting the importance of identifying an individual's travel history within the previous year. Multiple other smaller studies have also evaluated the risk of ESBL-PE acquisition while travelling (7). The average risk of ESBL-PE colonization after travel is 643 per 1,000 travellers from the Indian subcontinent, 340 per 1,000 travellers from Africa and 186 per 1,000 travellers from Central and South America (Figure 1). Although the majority of studies focus on the risk of colonization with drug-resistant organisms, recent travel has been associated with an increased risk of ESBL-PE urinary tract infections (8-11) and bacteremia with ESBL-PE post-transrectal prostate biopsy (12).

\section{Carbapenem-resistant Enterobacteriacae (CRE)}

CRE infections, which have also been increasing around the world, are of particular concern due to the limited treatment options and the high infection-related mortality rates of $40 \%$ to $70 \%(13,14)$. The three main classes of carbapenemase-producing Enterobacteriaceae that confer carbapenem resistance have distinct regional epidemiology (15):

- Klebsiella pneumoniae carbapenemase (KPC) is the most common carbapenemase-producing Enterobacteriaceae in North America

- OXA-48-like carbapenemases are typical in Turkey and surrounding regions

- New Delhi Metallo-beta-lactamase-1 (NDM-1) was initially associated with those who had received medical care in the Indian subcontinent, but has since been reported in every continent (16)

Figure 1: The number of extended spectrum beta-lactamase (ESBL) producing and carbapenem-resistant Enterobacteriaceae (CRE) per 1,000 travellers by region visited

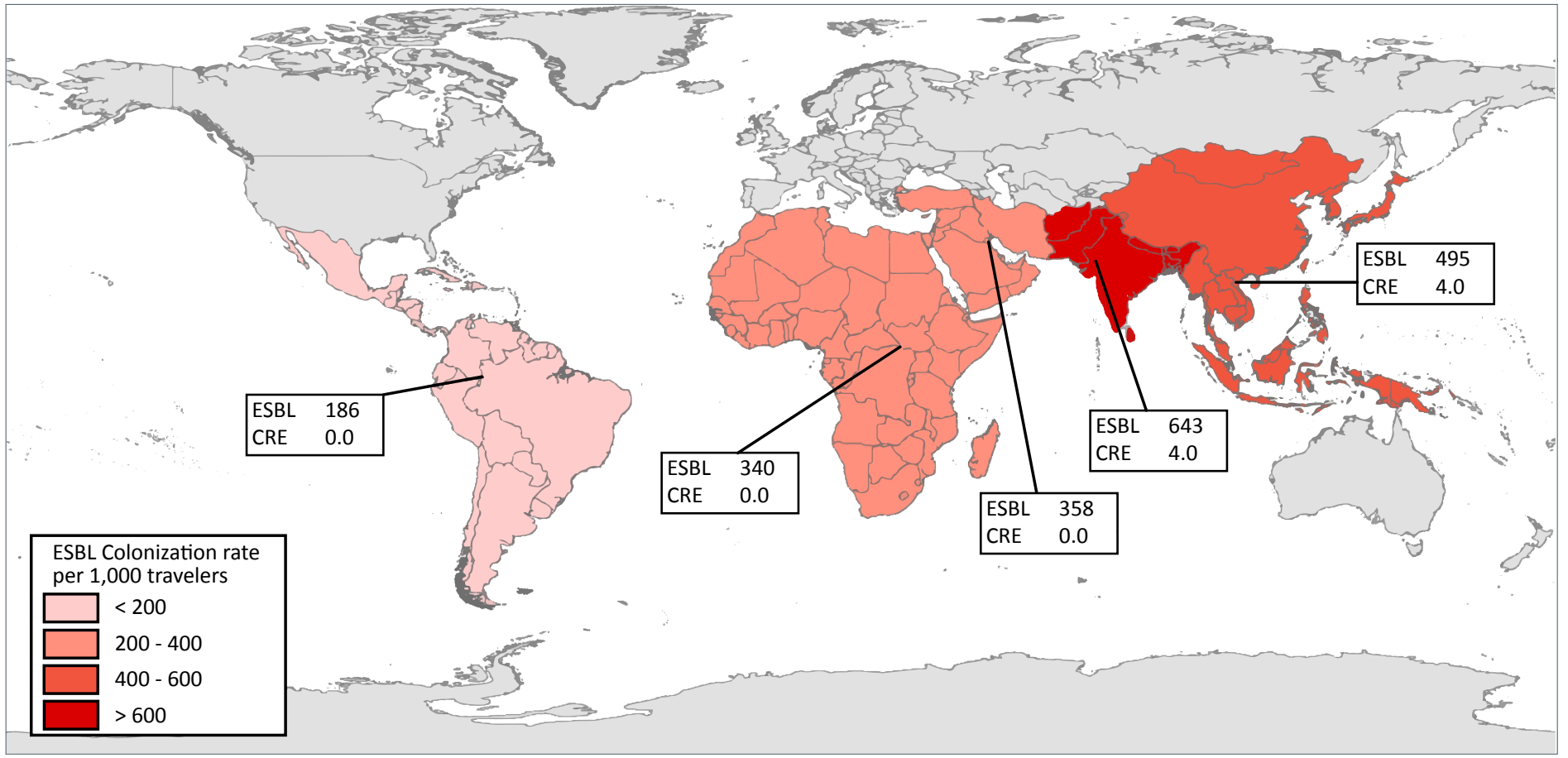

Abbreviations: $\mathrm{CRE}$, carbapenem-resistant Enterobacteriaceae; $\mathrm{ESBL}$, extended-spectrum beta-lactamase; $<$, inferior to; $>$, superior to

Note: Data for the figure derived from weighted average of published studies. Figure modified with permission from Schwartz \& Morris (7) 
The Canadian Nosocomial Infection Surveillance Program (CNISP) recently characterized carbapenemase-producing Enterobacteriaceae reported in hospitals across Canada from 2010 to 2014. The incidence was 0.07 cases per 1,000 admissions, with KPC and NDM-1 being the most common. Many of those affected had a history of international travel. India was the most common travel destination with $31 \%$ of cases reporting travel to that country within the previous 12 months (17). However, the risk of acquiring a CRE while travelling is considerably lower than the risk of acquiring an ESBL-PE (Figure 1).

\section{Colistin-resistance gene, $\mathrm{mcr}-1$}

Of further concern is the recently described plasmid-mediated colistin resistance gene $\mathrm{mcr}-1$ which can be co-located with other gram-negative resistance mechanisms. Colistin is one of few antibiotic options for managing CRE; however, it carries significant risk of nephrotoxicity and neurotoxicity. Initially discovered in animal and human clinical isolates in China, mcr-1 has now been reported in clinical isolates globally (18). A recent Dutch study found that $5 \%$ of long-distance travellers had $\mathrm{mcr}-1$ in fecal samples. These travellers had primarily visited southeast Asia or southern Africa (19).

Travel is also playing a role in the spread of other drug-resistant bacterial organisms such as Salmonella, Shigella and

Campylobacter species, which has been reviewed elsewhere (7).

\section{What are the risk factors for acquiring drug-resistant organisms while travelling?}

\section{Health care exposure}

Recent health care exposure abroad has been noted as a risk factor for acquiring a drug-resistant organism. In the CNISP evaluation of Canadian patients with CRE, of those with a travel history available, $86 \%$ had sought medical care abroad (17). The association between health care exposure while travelling and drug-resistant organisms has also been observed in a number of European studies (20-27). Among those returning home after being hospitalized abroad, colonization with any multidrug-resistant organism (MDRO) ranged from $7 \%(21)$ to $29 \%$ (23). In these studies, MDROs were defined as ESBL-PE, CRE, other multidrug-resistant gram-negative organisms, methicillin-resistant Staphylococcus aureus and vancomycin-resistant Enterococcus. The greatest risk was for patients who were transferred directly or repatriated from hospitals abroad compared to those not directly repatriated (odds ratio $[\mathrm{OR}]=7.4 ; 95 \% \mathrm{Cl}$ : 2.1-25.2) (27). Other risk factors include a longer hospital stay abroad $(20,21)$; history of a surgical procedure abroad (22); admission to a high-risk unit (i.e. intensive care unit) (21); tropical or subtropical country visited (particularly South Asia) $(21,24)$; and receipt of antibiotics while hospitalized (21-23).
Although these studies included travellers with either an elective or emergent reason for hospitalization, this risk is likely applicable to medical tourists, that is, those who travel abroad for the specific purpose of accessing medical care (28). Global estimates indicate that there are about four million medical tourists annually (29); a Canadian survey indicates that over 63,000 patients sought medical care abroad in 2016 (30). Most Canadian medical tourists seek care in the US, followed by low- and middle-income countries in the Americas and Asia (31), which includes regions with elevated rates of drug-resistance. Given the risk of acquiring drug-resistant organisms while travelling, particularly for individuals who access health care systems abroad, this poses an important and often underestimated risk for those who are considering medical tourism.

\section{Travellers' diarrhea}

Travellers' diarrhea is caused by ingesting contaminated food or beverages containing bacterial enteropathogens (32). Depending on the travel location and host factors, the incidence of diarrhea during travel can range from $10 \%$ to $40 \%$. In several studies of travellers acquiring drug-resistant organisms abroad, travellers' diarrhea was noted as a significant risk factor, particularly for acquiring an ESBL-PE. Travellers' diarrhea is associated with an approximate 2- to 3-fold increased risk of acquiring an ESBL-PE abroad $(6,33,34)$. In a study of Finnish travellers, this risk of acquiring an ESBL-PE was $11 \%$ in those without travellers' diarrhea, $21 \%$ in those with travellers' diarrhea who did not take antibiotics and $37 \%$ in those with travellers' diarrhea who were treated with antibiotics (33).

\section{Antibiotic exposure}

Antibiotics apply selective pressure to the native organisms colonizing the gut, increasing the risk that drug-resistant organisms contracted abroad are incorporated into the microbiome. Treatment with antibiotics has been repeatedly demonstrated to present a risk to travellers. In the previously mentioned Dutch study of travellers who acquired ESBL-PEs abroad, antibiotic use was associated with a greater than 2-fold risk of acquiring these drug-resistant organisms (OR=2.7; 95\% $\mathrm{Cl}$ : 1.8-4.0) (6). In a Finnish study, $21 \%$ of those who received no treatment, $20 \%$ of those treated with the anti-diarrheal medication loperamide alone, $40 \%$ of those treated with antibiotics alone and $71 \%$ of those treated with both loperamide and antibiotics became colonized with ESBL-PE (35).

Among travellers hospitalized abroad, the risk associated with antibiotic treatment was also pronounced, with an 11-fold higher risk of being colonized with an MDRO $(O R=10.7 ; 95 \%$ $\mathrm{Cl}$ : 4.2-27.3) compared to those who did not travel abroad; however, being hospitalized abroad and not receiving an antibiotic was not a risk factor for MDRO colonization in this study (26). The importance of antibiotic exposure during a travel-associated hospitalization is echoed in a large study in Finland, where risk of colonization with an MDRO was significantly increased in those receiving antibiotics $(O R=3.2$; 
$95 \% \mathrm{Cl}: 2.3-4.5)$ (23). Similarly, a study in the Netherlands found a 2.5- to 3.4-fold increased risk of gram-positive MDRO colonization in those who had been treated with antibiotics while hospitalized abroad (20).

\section{What can clinicians do to minimize harm in Canadian travellers?}

By understanding the risk of AMR associated with travel, health care professionals will be better able to implement approaches to improve management and reduce transmission of drug-resistant organisms as well as educate the public to make informed decisions (Figure 2). Opportunities for clinicians include:

- Counselling patients, pretravel, on the risk of acquiring a drug-resistant organism, tailored to the patient's itinerary and specific region of travel (Figure 1)

- Counselling patients on the risks of unplanned health care exposure abroad; minimizing the risk through pretravel immunizations and counselling on how to prevent travellers' diarrhea and avoid high risk activities

- Counselling patients on the risks of medical tourism, tailored to the patient's itinerary and specific region of travel (Figure 1)

- When considering a prescription for anticipatory travellers' diarrhea prior to travel, given the risk of acquiring an ESBL-PE, understanding that recent guidelines encourage supportive care only for mild travellers' diarrhea and that antibiotic prophylaxis for travellers' diarrhea is indicated only in select patients at high risk for complications (36); and

- Considering recent travel (within the past 12 months) when selecting empirical antimicrobial therapy for patients who have a severe infection (patients who have travelled to Asia, particularly the Indian subcontinent, should be considered at very high risk for drug-resistant Enterobacteriaceae)

Figure 2: Opportunities to manage risk of acquiring drug-resistant organisms from travelling

\begin{tabular}{|c|c|}
\hline tru & $\begin{array}{l}\text { - Counsel patients about the risks of acquiring a drug-resistant } \\
\text { organism tailored to their itinerary and region of travel }\end{array}$ \\
\hline uring & $\begin{array}{l}\text { - Reserve antibiotics for those with moderate or severe } \\
\text { travellers' diarrhea and discourage use of antibiotics for mild } \\
\text { travellers' diarrhea or prophylaxis }\end{array}$ \\
\hline $\begin{array}{l}\text { Post } \\
\text { travel }\end{array}$ & $\begin{array}{l}\text { - Take a travel history that includes the previous } 12 \text { months to } \\
\text { should inform empiric antibiotic choices for patients with } \\
\text { severe infections }\end{array}$ \\
\hline
\end{tabular}

\section{Conclusion}

Travelling abroad carries a significant risk for acquiring a drug-resistant organism. Asia and the Indian subcontinent in particular present the greatest risks for acquiring an ESBL-PE or CRE. Medical care, travellers' diarrhea and antibiotic use abroad further increase the risks for travellers. Health care professionals can play an important role in reducing the risk for travellers through counselling, appropriate antibiotic prescribing and tailored empirical therapy for patients presenting with severe infections who have travelled recently.

\section{Conflict of interest}

None.

\section{Acknowledgements}

We would like to thank Sean Marshall from Public Health Ontario for creating the map figure.

\section{References}

1. O'Neill J. Review on antimicrobial resistance antimicrobial resistance: tackling a crisis for the health and wealth of nations. London: Review on Antimicrobial Resistance; 2014. https://amr-review.org/sites/default/files/AMR\%20 Review\%20Paper\%20-\%20Tackling\%20a\%20crisis\%20for\%20 the\%20health\%20and\%20wealth\%20of\%20nations_1.pdf

2. ResistanceMap. Washington (DC): Center for Disease Dynamics, Economics \& Policy (CDDEP). https:// resistancemap.cddep.org/

3. Annual Review IA. 2018. Geneva: International Air Transport Association; 2018. https://www.iata.org/media/ annual-report-2018/index.html

4. Schwaber MJ, Navon-Venezia S, Kaye KS, Ben-Ami $\mathrm{R}$, Schwartz D, Carmeli Y. Clinical and economic impact of bacteremia with extended-spectrum-bet a-lactamase-producing Enterobacteriaceae. Antimicrob Agents Chemother 2006 Apr;50(4):1257-62. DOI PubMed

5. Xu L, Sun X, Ma X. Systematic review and meta-analysis of mortality of patients infected with carbapenem-resistant Klebsiella pneumoniae. Ann Clin Microbiol Antimicrob 2017 Mar;16(1):18. DOI PubMed

6. Arcilla MS, van Hattem JM, Haverkate MR, Bootsma MC van Genderen PJ, Goorhuis A, Grobusch MP, Lashof AMO, Molhoek N, Schultsz C, Stobberingh EE, Verbrugh HA, de Jong MD, Melles DC, Penders J. Import and spread of extended-spectrum B-lactamase-producing Enterobacteriaceae by international travellers (COMBAT study): a prospective, multicentre cohort study. Lancet Infect Dis 2017 Jan;17(1):78-85. DOI PubMed

7. Schwartz KL, Morris SK. Travel and the spread of drug-resistant bacteria. Curr Infect Dis Rep 2018 Jun;20(9):29. DOI PubMed

8. Osthoff M, McGuinness SL, Wagen AZ, Eisen DP. Urinary tract infections due to extended-spectrum beta-lactamaseproducing Gram-negative bacteria: identification of risk factors and outcome predictors in an Australian tertiary referral hospital. Int J Infect Dis 2015 May;34:79-83. DOI PubMed 
9. Søraas A, Sundsfjord A, Sandven I, Brunborg C, Jenum PA. Risk factors for community-acquired urinary tract infections caused by ESBL-producing enterobacteriaceae--a case-control study in a low prevalence country. PLoS One 2013 Jul;8(7):e69581. DOI PubMed

10. Talan DA, Takhar SS, Krishnadasan A, Abrahamian FM, Mower WR, Moran GJ; EMERGEncy ID Net Study Group. Fluoroquinolone-resistant and extended-spectrum beta-lactamase-producing Escherichia coli infections in patients with pyelonephritis, United States(1). Emerg Infect Dis 2016 Sep;22(9): DOI PubMed

11. Tham J, Odenholt I, Walder M, Andersson L, Melander E. Risk factors for infections with extended-spectrum beta-lactamase-producing Escherichia coli in a county of Southern Sweden. Infect Drug Resist 2013 Sep;6:93-7. DOI PubMed

12. Patel U, Dasgupta P, Amoroso P, Challacombe B, Pilcher J, Kirby R. Infection after transrectal ultrasonography-guided prostate biopsy: increased relative risks after recent international travel or antibiotic use. BJU Int 2012 Jun;109(12):1781-5. DOI PubMed

13. Ben-David D, Kordevani R, Keller N, Tal I, Marzel A, Gal-Mor O, Maor Y, Rahav G. Outcome of carbapenem resistant Klebsiella pneumoniae bloodstream infections. Clin Microbiol Infect 2012 Jan;18(1):54-60. DOI PubMed

14. Friedman ND, Carmeli Y, Walton AL, Schwaber MJ. Carbapenem-resistant Enterobacteriaceae: a strategic roadmap for infection control. Infect Control Hosp Epidemiol 2017 May;38(5):580-94. DOI PubMed

15. van Duin $D$, Doi $Y$. The global epidemiology of carbapenemase-producing Enterobacteriaceae. Virulence 2017 May;8(4):460-9. DOI PubMed

16. Wilson ME, Chen LH. NDM-1 and the role of travel in its dissemination. Curr Infect Dis Rep 2012 Jun;14(3):213-26. DOI PubMed

17. Mataseje LF, Abdesselam K, Vachon J, Mitchel R, Bryce E, Roscoe D, Boyd DA, Embree J, Katz K, Kibsey P, Simor AE, Taylor G, Turgeon N, Langley J, Gravel D, Amaratunga K, Mulvey MR. Results from the Canadian Nosocomial Infection Surveillance Program on Carbapenemase-Producing Enterobacteriaceae, 2010 to 2014. Antimicrob Agents Chemother 2016 Oct;60(11):6787-94. DOI PubMed

18. Mediavilla JR, Patrawalla A, Chen L, Chavda KD, Mathema B, Vinnard C, Dever LL, Kreiswirth BN. Colistin- and carbapenem-resistant Escherichia coli harboring mcr1 and blaNDM-5, causing a complicated urinary tract infection in a patient from the United States. MBio 2016 Aug;7(4):e01191-16. DOI PubMed

19. von Wintersdorff CJ, Wolffs PF, van Niekerk JM, Beuken E, van Alphen LB, Stobberingh EE, Oude Lash of AM, Hoebe CJ, Savelkoul PH, Penders J. Detection of the plasmid-mediated colistin-resistance gene mcr-1 in faecal metagenomes of Dutch travellers. J Antimicrob Chemother 2016 Dec;71(12):3416-9. DOI PubMed

20. Kaiser AM, Schultsz C, Kruithof GJ, Debets-Ossenkopp Y, Vandenbroucke-Grauls C. Carriage of resistant microorganisms in repatriates from foreign hospitals to The Netherlands. Clin Microbiol Infect 2004 Nov;10(11):972-9. DOI PubMed

21. Josseaume J, Verner L, Brady WJ, Duchateau FX. Multidrug-resistant bacteria among patients treated in foreign hospitals: management considerations during medical repatriation. J Travel Med 2013 Jan-Feb;20(1):22-8. DOI PubMed

22. Kaspar T, Schweiger A, Droz S, Marschall J. Colonization with resistant microorganisms in patients transferred from abroad: who needs to be screened? Antimicrob Resist Infect Control 2015 Jul;4:31. DOI PubMed

23. Khawaja T, Kirveskari J, Johansson S, Väisänen J, Djupsjöbacka A, Nevalainen A, Kantele A. Patients hospitalized abroad as importers of multiresistant bacteria-a cross-sectional study. Clin Microbiol Infect 2017 Sep;23(9):673.e1-8. DOI PubMed

24. Mutters NT, Günther F, Sander A, Mischnik A, Frank U. Influx of multidrug-resistant organisms by country-to-country transfer of patients. BMC Infect Dis 2015 Oct; 15:466. DOI PubMed

25. Nemeth J, Ledergerber B, Preiswerk B, Nobile A, Karrer $S$, Ruef C, Kuster SP. Multidrug-resistant bacteria in travellers hospitalized abroad: prevalence, characteristics, and influence on clinical outcome. J Hosp Infect 2012 Dec;82(4):254-9. DOI PubMed

26. Angue $M$, Allou $N$, Belmonte $O$, Lefort $Y$, Lugagne N, Vandroux D, Montravers P, Allyn J. Risk factors for colonization with multidrug-resistant bacteria among patients admitted to the intensive care unit after returning from abroad. J Travel Med 2015 Sep-Oct;22(5):300-5. DOI PubMed

27. Birgand G, Armand-Lefevre L, Lepainteur M, Lolom I, Neulier C, Reibel F, Andremont A, Lucet JC. Introduction of highly resistant bacteria into a hospital via patients repatriated or recently hospitalized in a foreign country. Clin Microbiol Infect 2014 Nov;20(11):O887-90. DOI PubMed

28. Lunt N, Carrera P. Medical tourism: assessing the evidence on treatment abroad. Maturitas 2010 May;66(1):27-32. DOI PubMed

29. Smith R, Martínez Álvarez M, Chanda R. Medical tourism: a review of the literature and analysis of a role for bi-lateral trade. Health Policy 2011 Dec;103(2-3):276-82. DOI PubMed

30. Ren F, Labrie Y. Leaving Canada for Medical Care. Fraser Research Bulletin. Vancouver (BC):Fraser Institute; 2017.

31. Runnels V, Labonté R, Packer C, Chaudhry S, Adams O, Blackmer J. Canadian physicians' responses to cross border health care. Global Health 2014 Apr;10:20. DOI PubMed

32. Steffen R, Hill DR, DuPont HL. Traveler's diarrhea: a clinical review. JAMA 2015 Jan;313(1):71-80. DOI PubMed

33. Kantele A, Lääveri T, Mero S, Vilkman K, Pakkanen SH, Ollgren J, Antikainen J, Kirveskari J. Antimicrobials increase travelers' risk of colonization by extended-spectrum betalactamase-producing Enterobacteriaceae. Clin Infect Dis 2015 Mar;60(6):837-46. DOI PubMed 
34. Vading $M$, Kabir $M H$, Kalin $M$, Iversen A, Wiklund $S$, Nauclér P, Giske CG. Frequent acquisition of low-virulence strains of ESBL-producing Escherichia coli in travellers. J Antimicrob Chemother 2016 Dec;71(12):3548-55. DOI PubMed

35. Kantele A, Mero S, Kirveskari J, Lääveri T. Increased risk for ESBL-producing bacteria from co-administration of loperamide and antimicrobial drugs for travelers' diarrhea. Emerg Infect Dis 2016 Jan;22(1):117-20. DOI PubMed

36. DuPont $\mathrm{HL}$, Steffen R. Use of antimicrobial agents for treatment and prevention of travellers' diarrhoea in the face of enhanced risk of transient fecal carriage of multi-drug resistant enterobacteriaceae: setting the stage for consensus recommendations. J Travel Med 2017 Aug;24(Suppl_1):S57-S62. DOI PubMed

Canada Communicable Disease Report

\section{VISUAL ABSTRACT}

\section{WHAT is the risk?}

The most common is resistant

Enterobacteriacea that can cause:

- travellers' diarrhea

- bronchitis/pneumonia

- urinary tract infections

Travellers may also become a carrier and pass it on to others

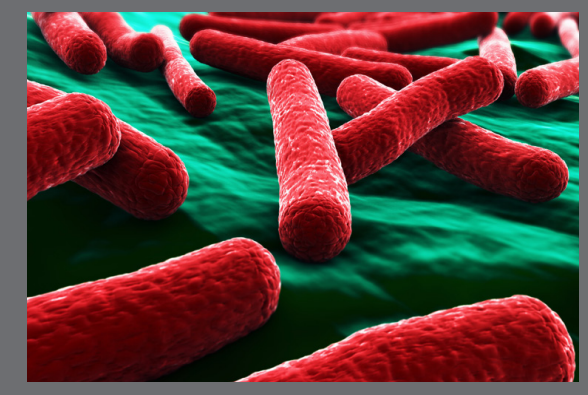

\section{WHERE is the risk?}

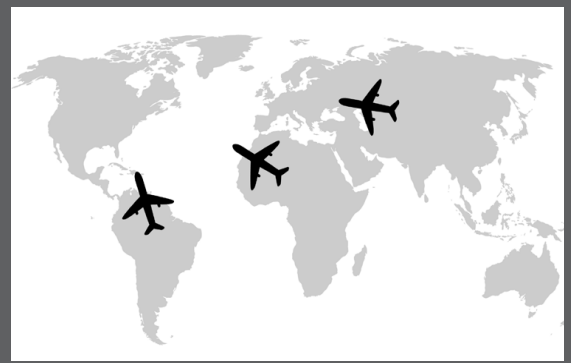

Highest Risk:

- Asia, especially the south

Also in:

- Africa and the Middle East

- The Caribbean and Central America

- South America

\section{Best practices}

Ask about travel in the past year

- especially in those with an infection unresponsive to antibiotics

Educate patients regarding:

- risk areas, hand hygiene and safe food practices

- symptomatic treatment of mild diarrhea

- minimal use of healthcare services

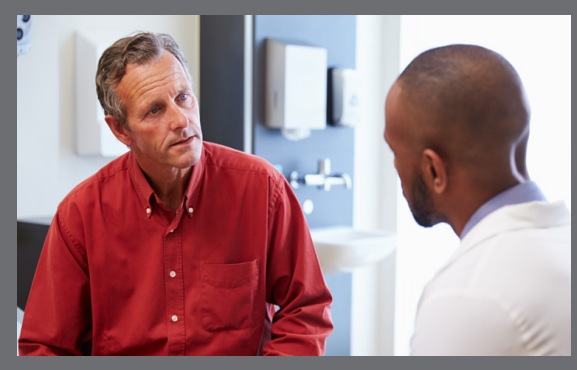

